\title{
Talent cap module: the implementation of digital and non-digital assessment game in collaborative learning environment
}

\author{
Nurul Hidayah Mat Zain ${ }^{1^{*}}$, Idris Osman ${ }^{2}$, Rachel Samuel ${ }^{3}$, Suhailah Kassim ${ }^{3}$, Suraya Hamimi \\ Mastor $^{3}$ and Halimahton Borhan ${ }^{4}$ \\ Senior Lecturer of Computer and Mathematical Sciences, UiTM Cawangan Melaka, Kampus Jasin, 77300 \\ Merlimau, Melaka ${ }^{1}$ \\ Lecturer of Business and Management, UiTM Cawangan Melaka, Kampus Bandaraya Melaka, 110 Off, Jalan Hang \\ Tuah, 75300, Melaka² \\ Senior Lecturer of Business and Management (Human Resource Management), UiTM Cawangan Melaka ${ }^{3}$ \\ Associate Professor of Business and Management (Human Resource Management), UiTM Cawangan Melaka ${ }^{4}$
}

Received: 08-October-2020; Revised: 02-March-2021; Accepted: 04-March-2021

(C)2021 Nurul Hidayah Mat Zain et al. This is an open access article distributed under the Creative Commons Attribution (CC BY) License, which permits unrestricted use, distribution, and reproduction in any medium, provided the original work is properly cited.

\begin{abstract}
Integrating the digital and non-digital assessment games for use in the classroom can enhance the user experience even when the course is challenging. Therefore, this study explores the user experience when a Talent Cap Module (TCM) is implemented in the Talent Recruitment and Selection course. The TCM consists of two types of significant components, digital assessment games: Talent Race and Talent Feud and non-digital assessment games: Talent Mind and Talent Gram. The students answered a questionnaire based on the MEEGA+ model after they experienced the TCM module. The study findings indicated that the TCM enhanced the engaging experience of learning the Talent Recruitment and Selection course. Keenly, the results of the study will emphasize games as an approach to learning non-computer science subjects.
\end{abstract}

\section{Keywords}

Assessment game, User experience, Talent cap module, MEEGA+ model, Engagement.

\section{Introduction}

Educational institutions' development became a pervasive concern in students' acquisition of specific and general knowledge and skillsets [1, 2]. Responding to competitive technology and industry needs, higher institutions extensively use collaborative learning approaches to support students' diverse learning styles, preferences, and interests $[2,3]$. The growing interest in collaborative learning emphasizes collaboration, and the team is learning in supporting the pedagogy form of learning activities. Face-to-face classrooms and technologybased learning is a central collaborative learning approach.

\footnotetext{
*Author for correspondence
}

This work was sponsored by the Ministry of Higher Education, Malaysia, using the Fundamental Research Grant Scheme (FRGS) funding 600-IRMI/FRGS 5/3 (210/2019).

496
These approaches strongly connect to learners' learning flexibility, high intrinsic satisfaction, engagement, and academic performance [4]. Through the face-to-face session, learners gained knowledge and skills through perceptions, group task performance, and social interaction.

According to [5], technology-based learning applies communication and information technologies to facilitate learners' learning processes and knowledge sharing.

This research was undertaken when observation by lecturers revealed students' difficulty to remember the terms used in the Talent Recruitment and Selection course offered to third-semester Human Resource Management undergraduate students. The course covers a large content of recruitment and selection practices at the workplace, which HR students must familiarize themselves with. Students were also unable to perform well in this course, causing a drop 
in their overall accumulative grades. This issue became even more pertinent with the pandemic issue in the country. As all Higher Education Institutes had to go online, teaching courses like Talent Recruitment and Selection became a bigger challenge. New methods of engaging students took priority, and games were incorporated as part of the course delivery method. However, it is equally important to evaluate the students' experience of this new method of delivery for qualitative courses. This scenario is useful for future planning for this course and whether incorporating games would be useful for other management/social science courses.

Underlying learners' diverse learning styles and preferences can be generated through technology intervention. Their positive perceptions and feelings on learning experiences should not fully replace faceto-face sessions [1, 5]. Although technology is found to play a predominant role in today's education, the lack of students' interactions and communication channels with one another reflects a symptom of low levels of learning engagement and enjoyment [6-10]. The extreme movement of conventional classrooms to the virtual learning environment has caused achievement, intellectual and competency skills, and attitude gaps in managing the transmission of knowledge and skills development [8]. Among the intellectual and competency skills, gaps are critical thinking, creativity, innovation, negotiations, teamwork, problem-solving, and decision-making [7, 10].

Meaningful collaborative learning requires the development of cognitive and affective behaviours, competencies, and intellectual skills to produce better learning preferences, experiences, and enjoyment in the lessons [6, 11]. These components can be developed through students' interactional collaborative activities using group-based projects, simulations, and games [12]. Research on collaborative learning has been mostly restricted to limited project-based learning, explicitly using games to help students achieve excellent academic results. Games are increasingly a popular learning paradigm, particularly in development, socialization, and education. In many studies, incorporating games (digital and non-digital games) as a learning approach influenced learners' emotions, knowledge, cognitive investment, and active participation [13-15]. It is expected that game-based learning has grown in various fields, such as environmental, accounting, history, parenting, libraries, and culture, specifically, as learners need more excitement and experiences for their educational, behavioural, and social outcomes. [16-18].

Besides, digital games entertain, challenging students' thinking, negotiations, and emotional responses to increase learning motivation, engagement, and creativity [13-15], [19-21]. Pursuing non-digital games strengthen students' cognitive abilities, feedback, design-related, attitudinal communication. These attributes are crucial for a high degree of learning motivation [14], $[20,21]$. However, the efficiency of learning a traditional game relies on the simplification of the rules, role descriptions, and time-consuming. Isolating digital and non-digital games for education affects the outcomes of communication learning, and the complexity of system designs contributes to the risk of using uncommon methods among students and lecturers [13], [19-21]. Therefore, it is a necessity to study the complementary of digital and non-digital games to support the diverse learning environment and learners' learning experiences [14, 20, 22].

Learning experiences are closely related to the effectiveness of the games [14]. Games encourage players to develop learning experiences with peers by sharing common emotions, feelings, values, and ideas. The challenges of playing games determine players' goal achievability and learning engagement. The engaging learning experience of game playing is contributed to the practical principles or approaches embedded in the game designs to facilitate positive learning outcomes [23]. A few models provide a systematic approach to evaluate motivation, learning, and player experiences. A well-developed model, such as MEEGA+ Model, evaluates games (digital and non-digital games), mainly on students' reactions after they finish playing the games [24]. Therefore, the study's objective is to evaluate students' user experience when the gamified module called Talent Cap Module (TCM) was implemented in the Talent Recruitment and Selection course. The results of this study can enhance the traditional learning approach and improve motivation for the students.

\section{Literature review}

\subsection{Digital and non-digital assessment games}

Games are often looked at as a system where players engage in a challenge defined by rules, interactivity, and feedback. What makes games interesting is that it results in a quantifiable outcome, often evoking an emotional response $[25,26]$. Students from Gen $Z$ and the Millennials are easily bored with the traditional one-way assessment methods. Hence, 
gamified assessment is a much-awaited alternative as it is more challenging and stimulating [27]. Collaborative learning methods are now commonly used to make students more interested in learning and actively contribute to classroom sessions. Collaborative learning as a learning method allows each student to contribute and share their ideas actively, and this is looked at as a positive outcome by both educators and learners.

Both digital and non-digital games can be used as assessment tools. These games promote a studentcentered, attractive, and interactive approach to classroom assessments. It is seen that games would be a positive alternative to traditional teaching methods and evaluating students' performance. However, it is pertinent to determine the experience of the users of these digital and non-digital games. The game experience is also known as the playergame interaction, and the focus is on the technical metrics and physiological aspects of the game evaluation. The experience of the users can be understood from three methodological categories: first, the quality of the product (game system experience), second, the quality of human-product interaction (individual player experience), and thirdly, the quality of this interaction in each social, spatial, temporal, or another context [28].

\subsection{Talent cap module}

Talent-CAP Module (TCM) is an acronym for Talent-Cognitive, Affective, Psychomotor Module developed to enhance students' academic performance who registers for the Talent Recruitment Selection course. This module incorporates digital teaching and learning delivery techniques (technology) and social collaboration to support students' knowledge and understanding of the subject content. The module is essential in improving three main domains: cognitive, affective, and psychomotor (CAP), strengthening communication skills, critical thinking, problem-solving, and students' presentation. The TCM has four components: 1) Talent Race; 2) Talent Feud; 3) Talent Mind; and 4) Talent Gram, which combines an assessment and learning delivery techniques digitally and social collaboration. Figure 1 showed the component of TCM.

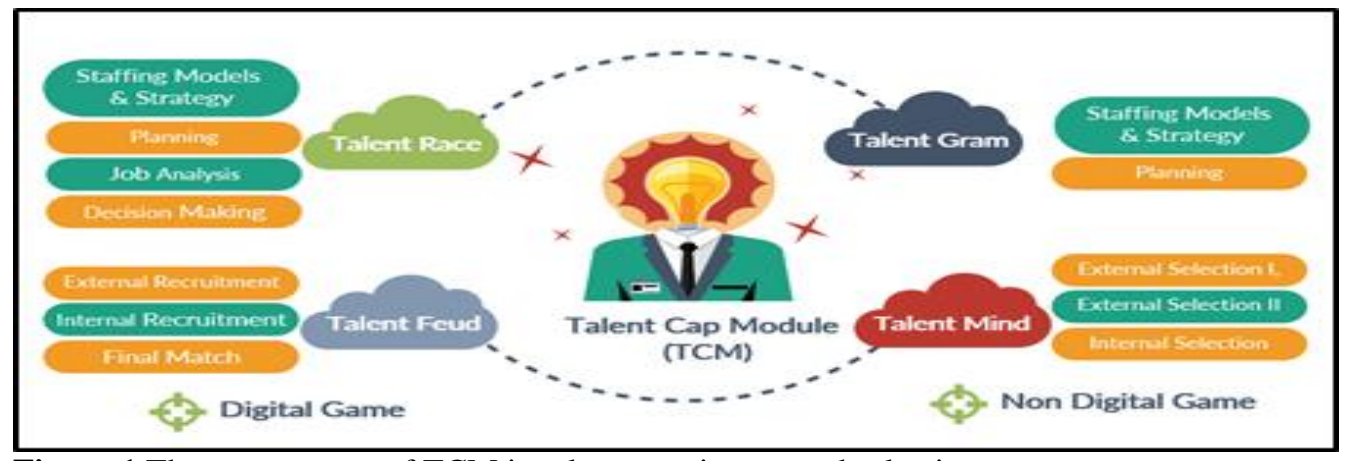

Figure 1 The components of TCM in talent recruitment and selection course

\subsubsection{Talent race}

Talent Race is an activity that uses gamified assessment applications in conventional learning. In line with the development of technology, e-learning is used to adapt to the evolution of unlimited learning using online applications and smartphone mediums. This digital game instills an understanding and knowledge of the course contents and then obtains students' responses to knowledge enhancement effectiveness. There are four topic's content delivered through Talent Race, namely Staffing Models and Strategy; Planning; Job Analysis; and Decision Making. The methods used existing gamified assessments in the market, Kahoot! and Quiznetic, to measure students' knowledge and understanding using preferred questions. Besides, to measure students' excitement towards the two platforms used, questionnaires are distributed to each student. The domains involved are cognitive (C1-Knowledge; $\mathrm{C} 2-$ Understanding; C4-Analysis); psychomotor domain (P3-Guided Response); and affective domain (A2Giving Feedback).

\subsubsection{Talent feud}

Talent Feud is an activity involving discussion and active communication of group members in discussing answers based on assessment from final exam questions. The questions tested include exact questions of the final examination for the past three semesters. The questions tested were popular, and each group's discussion stimulated critical thinking and high team spirit. There are three focused subject content, namely External Recruitment, Internal 
Recruitment, and Final Match. This activity supports students' efforts in revising the topics involved. The questionnaire items focused on the purpose of improving students' knowledge and understanding of the topics given. At the end of this game, students can know and understand the requirements of final exam questions and provide answers accurate and correctly for the topics of External Recruitment, Internal Recruitment, and Final Match. The domains involved are Cognitive Domains (C1-Knowledge; C2-Understanding).

\subsubsection{Talent mind}

Talent Mind is a mindset or can be defined as an instrument testing visual thinking that can help students analyze better and remember matters related to learning topics. This activity is carried out in a lecture room using a poster. This mind map learning instills an understanding and knowledge of the subject and obtains students' responses to knowledge enhancement effectiveness after using it. There are three focused topics, namely External Selection I, Selection External II, and Internal Selection. Talent Mind games measure students' level of knowledge and understanding in organizing answers based on their topics.

Moreover, it is to measure student stimulation level, arranging ideas for each given answer, testing the level of critical thinking in groups to discuss the accuracy of answers. At the end of this game, students can arrange ideas and learning concepts in mind map format. The domains involved are cognitive (C1-Knowledge; C2-Understanding); and psychomotor domain (P3-Guided Response). Also, students are expected to understand the association between ideas and concepts in mind map format, and it makes it easier to remember information related to learning topics.

\subsubsection{Talent gram}

Talent Gram is an acronym for talent diagrams involving diagrams used by this course. Students should understand and illustrate the diagrams used in the recruitment and selection process of employees, as this is the basis and firm guidance to achieve the organization's goals. There are two main topics used for this activity, namely Staffing Model and Strategy and Planning. Students should master the diagram/model to achieve excellent and satisfactory final testing and examination performance. Besides, this activity emphasizes students' understanding of illustrating diagram/model knowledge in each topic in this course. Students need to gain useful knowledge and understanding to illustrate diagrams/models and describe processes or measures of various aspects of recruitment and employee selection. Students can illustrate diagrams used in recruitment processes/strategies and employee selection at the end of this game. The domains involved are cognitive (C1-Knowledge; C2Understanding).

\subsection{MEEGA+ model as evaluation model in TCM} MEEGA+ Model [24] is a prominent model developed to evaluate educational games. This model aims to motivate students to use games as learning material, generate educational perceptions, and provides a better player experience. This model assesses students' reactions after playing games (digital and non-digital). The assessments included quality factors such as motivation, player experience, and learning. The following are the elements that are implemented to evaluate TCM.

\subsubsection{Confidence}

To ensure the effectiveness of gamified assessment, students must have the confidence to solve the problems. Using high-level questions in the game is said to improve the task's performance, increase selfconfidence, and reduce anxiety, which leads to many advantages in the learning process. If students believe they have achieved deep learning levels throughout the course, they are more likely to express confidence in their future ability to utilize what has been learned in the course.

2.3.2 Challenge

In designing instructional terms, the content should be presented in a challenging way, with subjective purpose and precise information about the steps and numerous logical options and routes the student could choose to finish the task [29]. Many studies show that students expect to experience mental challenges and real-time inputs in game-based learning and assessment. Palomino et al. [29] also suggest by bringing together the elements of structure with content, students, while wishing to have mental challenges and clear goals to follow, can use their senses and mentally immerse themselves in the tasks. The lack of instructions and consistent methods to construct techniques and implementations is one of the critical problems of its performance in the game sense. The first step is to set the stage to build the right challenge and the right team to solve it [30].

\subsubsection{Satisfaction}

Games can also create a positive memory and experience of learning for students in the classroom. Besides, the teacher uses rewards as an incentive to make the learners want to learn more. Hence, games are used as an educational innovation. Teaching methods using games are also used in science courses to stimulate students to be interested in it. This 
scenario will allow the learners to gain more knowledge and understanding because it could make students enjoy learning and attain the learning outcomes. The students would also have a sense of fulfillment and satisfaction.

\subsubsection{Social interaction}

There is growing interest in higher learning communities where institutional programs were designed to bring students together through shared educational experiences, often over extended periods and various settings. Although such initiatives date back to the early days of the 20th century [31], their recent resurgence coincides with their recognition by the Association of American Colleges and Universities as a high-impact educational practice their link to student engagement [32]. The success of these programs is based, in part, on the types of interactions among students. Traditionally, student interactions have been divided into two categories based on either social or academic integration [33]. More recent research based on positive psychology emphasizes overall well-being and meaning-making for students [34].

2.3.5 Fun

Gamified assessment is a fun way that helps students change their learning attitudes. The fun will help the students learn more effectively. In a fun setting for many learners, problems are solved, and obstacles are resolved when logical thinking skills are involved. Yue et al. [35] called these 'Desirable difficulties.' Besides, Lui [36] reported that students chose to learn vocabulary through technology not only because it was more fun and exciting but because it made it easier to remember vocabulary. This study confirms that the game can boost the learning experience. Gaming elements can make learning or assessment for students more fun and exciting. Thus, it is a possible learning process method of growing student motivation and engagement to improve learning quality due to using games in the assessment.

2.3.6Focused attention

Attention means focusing and concentrating on one's mind. If concentrated attention is given, a person may respond to particular objects visually, audibly, tacitly, or in some other way that he/she can alter the environment. When students cannot focus on learning, they have substantially lowered the performance rate of learning tasks [37]. The use of successful concentration techniques to maximize student attention positively affects and enhances student performance in the teaching process. Attention strategies have had a noticeable impact. This scenario provides learners with a more significant opportunity to involve in the process of learning. It provides teachers and students with more opportunities to actively participate in teaching and learning [38].

\subsubsection{Relevance}

Relevance is an abstract term that is not easy to define. It is an essential element in the education literature. However, this concept is hardly explained in detail. It can generally be understood as something important, exciting, and worth knowing. The theory of relevance was put forth in the mid-80s [24], which posits: "...the search for relevance is a basic feature of human cognition...." Relevance is vital to teaching and learning because it directly relates to student engagement and motivation $[39,40]$. When a student feels that something is relevant, he/she would be motivated to perform better by engaging actively in the activity.

2.3.8 Perceived learning

When a student reports his/her knowledge gain based on his/her reflection and introspection, this can be understood as 'perceived learning' [41]. Perceived learning can be used as an indicator of learning, and the strongest and most significant predictor of perceived online learning is self-efficacy [42]. The two dimensions of perceived learning are knowledge acquisition and knowledge transfer. Knowledge acquisition is defined as a collection of newly acquired knowledge, and it is related to retention. On the contrary, knowledge transfer would mean that the learner can understand the new knowledge to a level that he/she can use it in other contexts and situations [43]. In other words, knowledge transfer would refer to the applicability of the knowledge in a different situation or context. A study conducted at three universities located in the USA, Spain, and China found that knowledge acquisition and knowledge transfer have a strong correlation with learning content and course design [44].

\section{Methodology}

TCM development involved four stages: 1) Ideas of Generation (idea generation and screening, and concept development); 2) Product Analysis and Product Development; 3) Pilot Tests, and 4) Final Product. The project's development involving generating ideas, content, materials, group creativity, energy, and costs. There were three attempts involved in TCM development to seek feedback and comments on this module's effectiveness. The module's improvement has considered the content, cost, and timing flow of the game, designs, and responsibilities of team members (facilitators/moderators) and students (players). 


\subsection{Participants}

The participants were undergraduate students who have registered for the Talent Recruitment and Selection Course at Universiti Teknologi MARA (UiTM) Cawangan Melaka, Kampus Bandaraya Melaka, and Kolej Yayasan MARA, Melaka. A total of 83 participants are involved in this study to evaluate the TCM in user experiences. The evaluation instrument was distributed online through Google Form to allow easy access to the participants. The voluntary responses by participants were then analyzed using SPSS software to generate descriptive data. Each of the participants was involved in all four components of the TCM. However, the total number of participants for the different components could be different. A few participants withdrew from the sessions because of other commitments, such as lectures and personal matters.

\subsection{Procedures}

There were eight procedures involved in evaluating TCM, as seen in Figure 2. On the day of the evaluation, participants were briefed about the detailed procedure. The demo was presented to the participants in each session. Participants need to access the digital game section through their mobile phones. There is no cut of time required for participants to complete their game. Once the participants completed the game, they were required to answer a post-questionnaire adapted from MEEGA+ Model [24]. They should answer it based on their experience while the instructor implemented TCM in the learning environment.

\subsection{Instrument}

The participants were given a MEEGA instrument adapted from [24]. The instrument's purpose is to evaluate the quality of educational games in terms of usability user experience. This study focuses only on measuring students' user experience when TCM was used in Talent Recruitment and Selection Course. Each item in the MEEGA model is given a scale of agreeability according to the Likert Scale ranging from 1=Strongly Disagree; 2=Disagree; 3=Neither Disagree or Agree; 4=Agree and 5=Strongly Agree. The prediction time to complete this questionnaire is about 10 minutes. Table 1 shows the list of questionnaire items in this study. The PL3 items in Perceived Learning elements are adapted based on the type of TCM that is implemented.

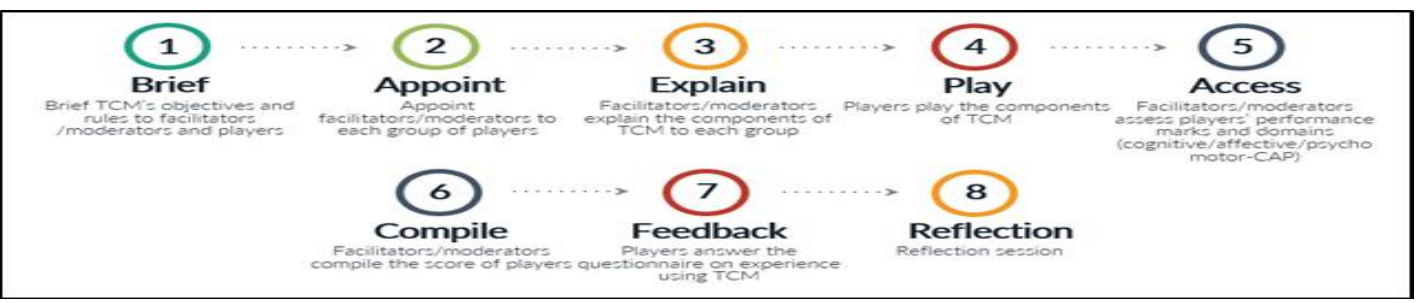

Figure 2 The procedure for evaluating TCM

Table 1 List of items in the questionnaire

\begin{tabular}{ll}
\hline Code & Item \\
\hline CO1 & The contents and structure helped me to become confident that I would learn with this game. \\
CH1 & This game is appropriately challenging for me. \\
CH2 & The game provides new challenges (offers new obstacles, situations, or variations) at an appropriate pace. \\
CH3 & The game does not become monotonous as it progresses (repetitive or boring tasks). \\
SA1 & Completing the game tasks gave me a satisfying feeling of accomplishment. \\
SA2 & It is due to my personal effort that I managed to advance in the game. \\
SA3 & I feel satisfied+ with the things that I learned from the game. \\
SA4 & I would recommend this game to my colleagues. \\
SI1 & I was able to interact with other players during the game. \\
SI2 & The game promotes cooperation and/or competition among the players. \\
SI3 & I felt good interacting with other players during the game. \\
FU1 & I had fun with the game. \\
FU2 & Something happened during the game (game elements, competition, etc.) which made me smile. \\
FA1 & There was something interesting at the beginning of the game that captured my attention. \\
FA2 & I was so involved in my gaming task that I lost track of time. \\
FA3 & I forgot about my immediate surroundings while playing this game. \\
RE1 & The game contents are relevant to my interests. \\
RE2 & It is clear to me how the contents of the game are related to the course. \\
RE3 & This game is an adequate teaching method for this course. \\
\hline
\end{tabular}




\begin{tabular}{ll}
\hline Code & Item \\
\hline RE4 & I prefer learning with this game to learning through other ways (e.g., other teaching methods). \\
PL1 & The game contributed to my learning in this course. \\
PL2 & The game allowed for efficient learning compared with other activities in the course. \\
PL3 & The game contributed to recall the concept from... \\
PL3 & The game contributed to recall the concept from... \\
\hline
\end{tabular}

\section{Result}

Table 2 shows the demography data. The results show that the participants are mainly females (60) (72.3\%). All participants are in the range of 18-29 years old. Based on demography data, 33 (39.8\%) participants play digital games weekly, which is at least once a month, and five respondents never play digital games. Meanwhile, 27 (32.5\%) out of 83 respondents play non-digital games weekly, 21 (25.3\%) monthly, and $6(7.2 \%)$ participants never play non-digital games. Only $4(4.8 \%)$ participants play the non-digital game every day, in contrast with $19(22.9 \%)$ playing digital games daily.

Table 2 List of items

\begin{tabular}{llcc}
\hline Question & Range & f & \% \\
\hline Gender & Male & 23 & 27.7 \\
Age group & Female & 60 & 72.3 \\
& Under 18 years & 0 & 0.0 \\
& 18 to 29 years & 83 & 100.0 \\
Institution & Over 30 years & 0 & 0.0 \\
& UiTM & 50 & 60.2 \\
How often do you play digital games? & KYM & Never & 39.8 \\
& Rarely: from time to time & 5 & 6.0 \\
& Monthly: at least once a month & 9 & 10.8 \\
How often do you play & Weekly: at least once a week & 17 & 20.5 \\
games (card or board games, etc.)? & Daily: every day & 33 & 39.8 \\
& Never & 19 & 22.9 \\
& Rarely: from time to time & 6 & 7.2 \\
& Monthly: at least once a month & 25 & 30.1 \\
& Weekly: at least once a week & 21 & 25.3 \\
& Daily: every day & 27 & 32.5
\end{tabular}

\subsection{Talent race}

4.1.1Kahoot!

The evaluation results regarding the participants' confidence using Kahoot! can be seen in Table 3. More than half $(60.6 \%)$ of participants agree or strongly agree that the contents and structure helped them become confident while learning through Kahoot! They believed the game reinforced their selfconfidence. Participants agreed and strongly agreed that they had fun through Kahoot! (97.6\%). They agreed and strongly agreed (94.0\%) that something that happened during the game made them smile. The fun and perceived learning elements received the highest mean value: $4.38(87.6 \%)$ in the Kahoot! session. Almost all participants agreed and strongly agreed $(94.0 \%)$ that Kahoot! contributed to assisting them in recalling the concepts in the Planning topic. Meanwhile, $93.8 \%$ of participants agreed and strongly agreed that they could recall the staffing model and Strategy topics through Kahoot!

\subsubsection{Quiznetic}

Table 4 presents user experience during the Talent Race (Quiznetic) implementation in assessing the Talent Recruitment and Selection course topics. Almost all participants agreed and strongly agreed $(95.7 \%)$ that they could interact with other players through Quiznetic. Besides, 90\% of participants agreed and strongly agreed that Quiznetic encouraged cooperation and competition among them. This scenario contributed to an excellent experience for the participants. Similar to the evaluation of Kahoot!, the Fun element gets the highest average mean value, which is $4.39(87.8 \%)$ in terms of agreeability compared to other elements such as Social Interaction $=4.36(87.2 \%)$, Satisfaction $=4.34$ $(86.8 \%)$ and Perceived Learning $=4.34(86.8 \%)$. Furthermore, items measuring the Confidence element had the lowest average mean, which is 4.24 $(84.8 \%)$ in terms of agreeability. This result indicated that the participants were less familiar with this game, which caused their confidence level to be the 
lowest compared to other elements. However, the Confidence element's agreeability as part of the excellent user experience contribution is still acceptable, with a percentage of more than $50.0 \%$. Based on the analysis of the overall average mean in the Talent Race session, participants agreed that Quiznetic contributed a more pleasurable experience compared to Kahoot!.

Table 3 Talent race evaluation for Kahoot!

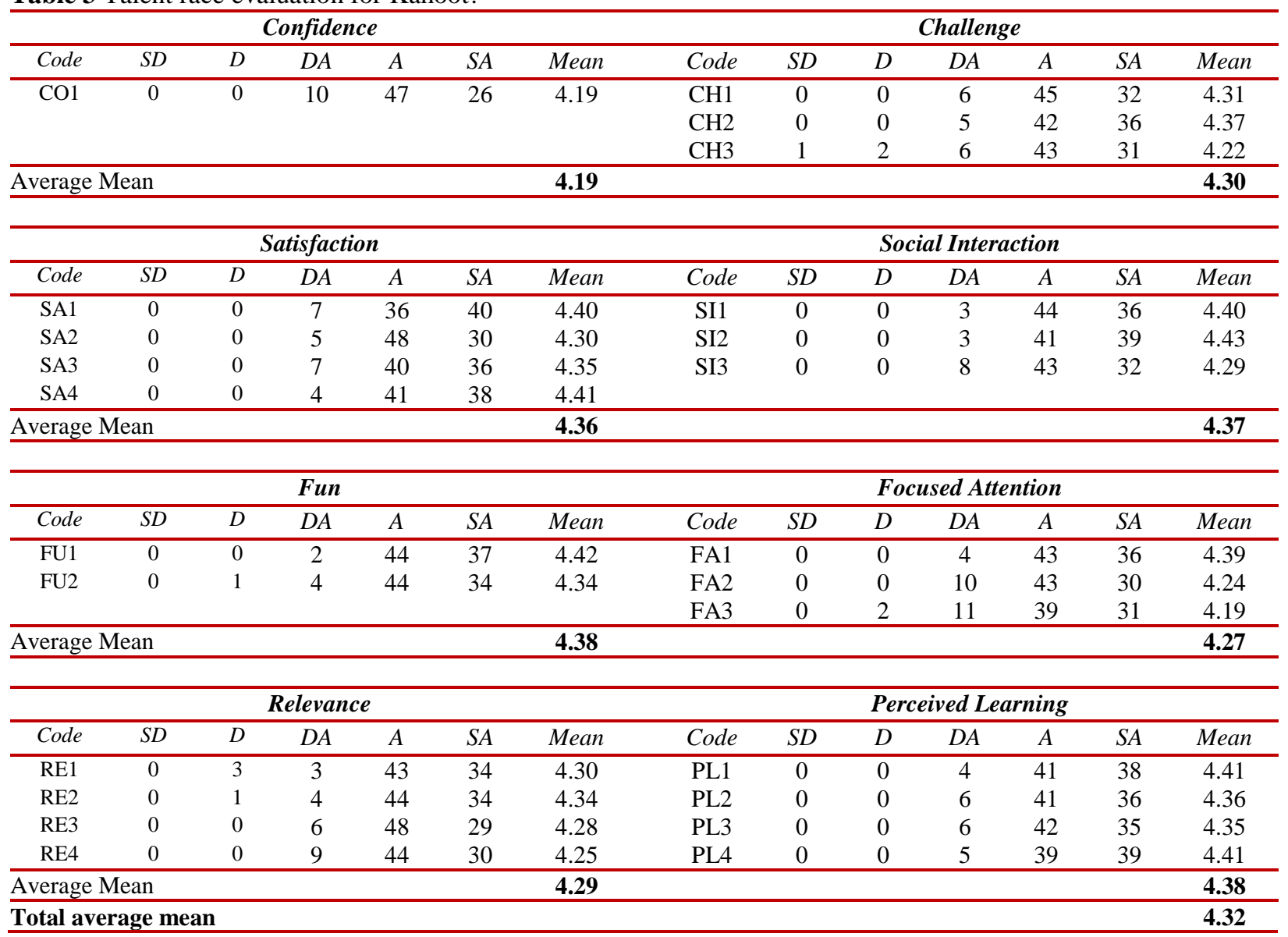

$\mathrm{SD}=$ Strongly Disagree $=$ Disagree, $\mathrm{DA}=$ Neither Disagree nor Agree, $\mathrm{A}=$ Agree, and SA=Strongly Agree.

Table 4 Talent race evaluation for Quiznetic

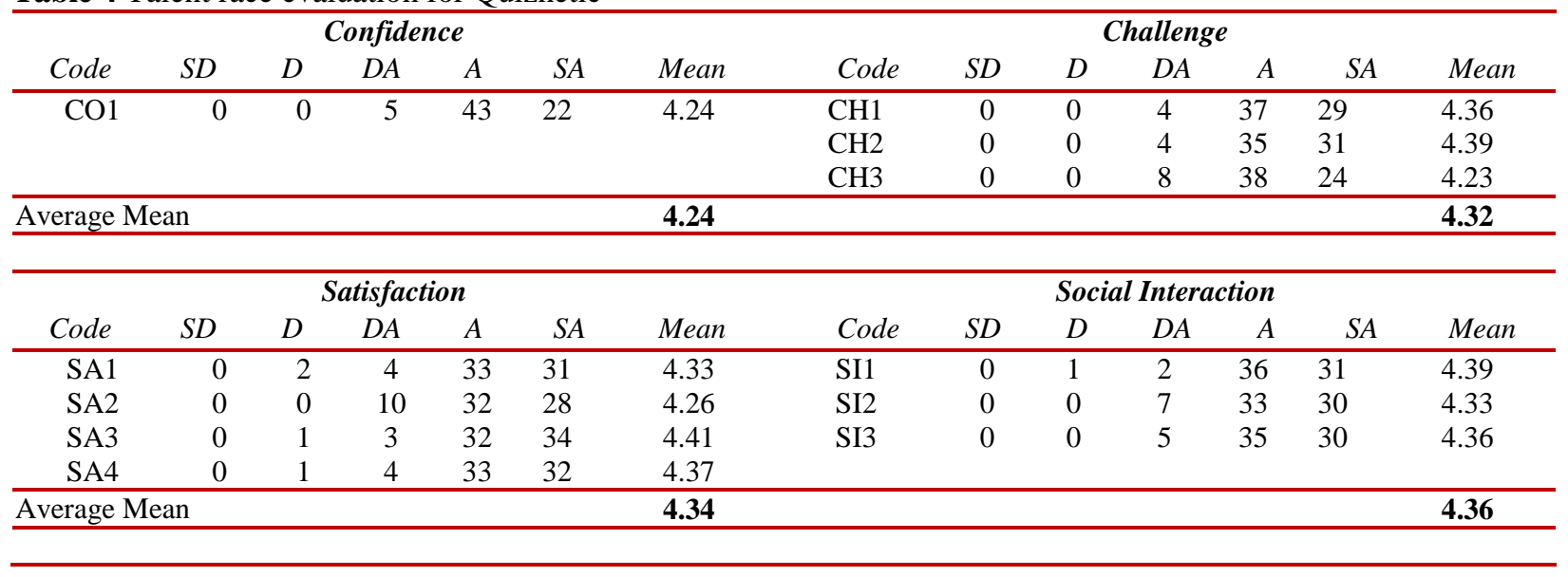


Nurul Hidayah Mat Zain et al.

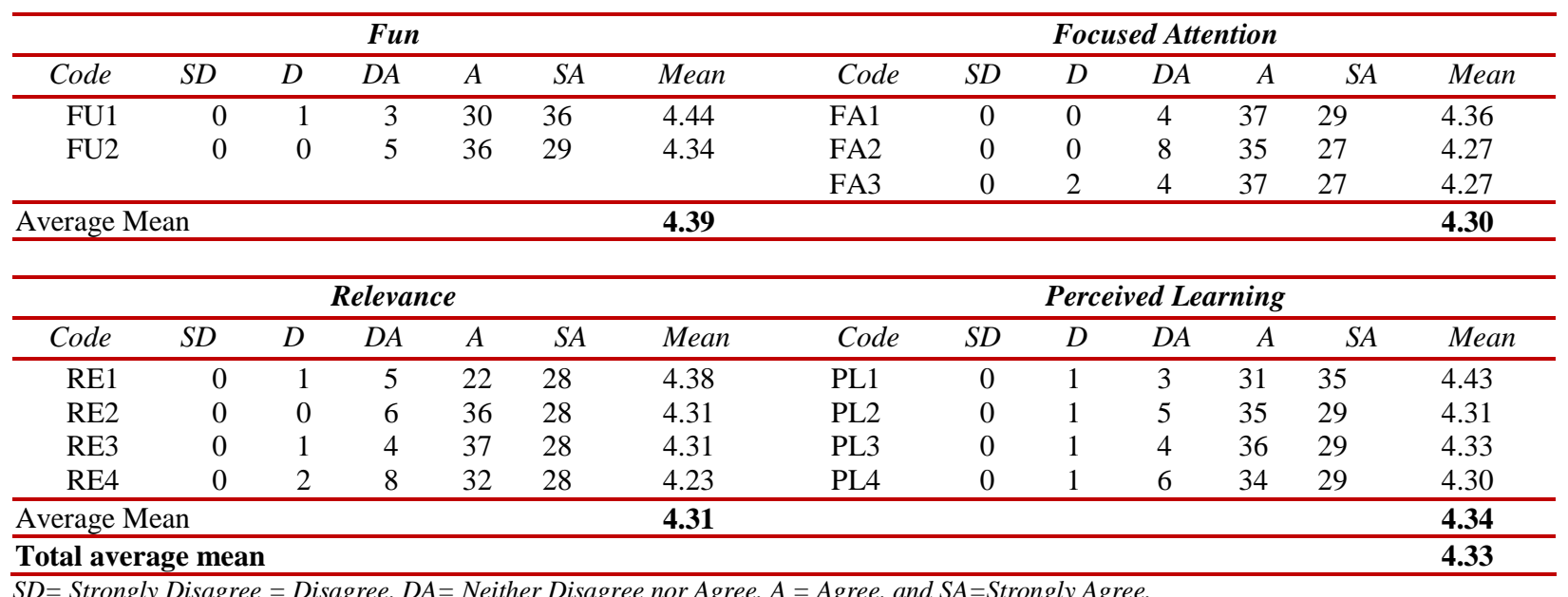

$S D=$ Strongly Disagree $=$ Disagree, $D A=$ Neither Disagree nor Agree, $A=A$ Aree, and SA=Strongly Agree.

\subsection{Talent feud}

Table 5 displays the results, which refer to evaluating participants' experience while Talent Feud was implemented at the learning session. Talent Feud is an example of a non-digital game as a learning tool. Talent Feud's Social Interaction element gets the highest agreeability $(88.0 \%)$ to contribute to user experience. The second highest element agreed and strongly agreed by participants that contributed to user experience is the Confidence element. Almost $97.0 \%$ of participants agreed that they were confident with Talent Feud's contents and structure that helped them learn. Almost $94.0 \%$ of the participants agreed and strongly agreed that the Talent Feud contents are related to the course. The analysis from Talent Feud's results indicated that $92.4 \%$ of participants agreed and strongly agreed that Talent Feud is an acceptable teaching method for the course. Besides, $93.9 \%$ of the participants prefer learning with Talent Feud to learning through other teaching methods.

Table 5 Talent Feud Evaluation

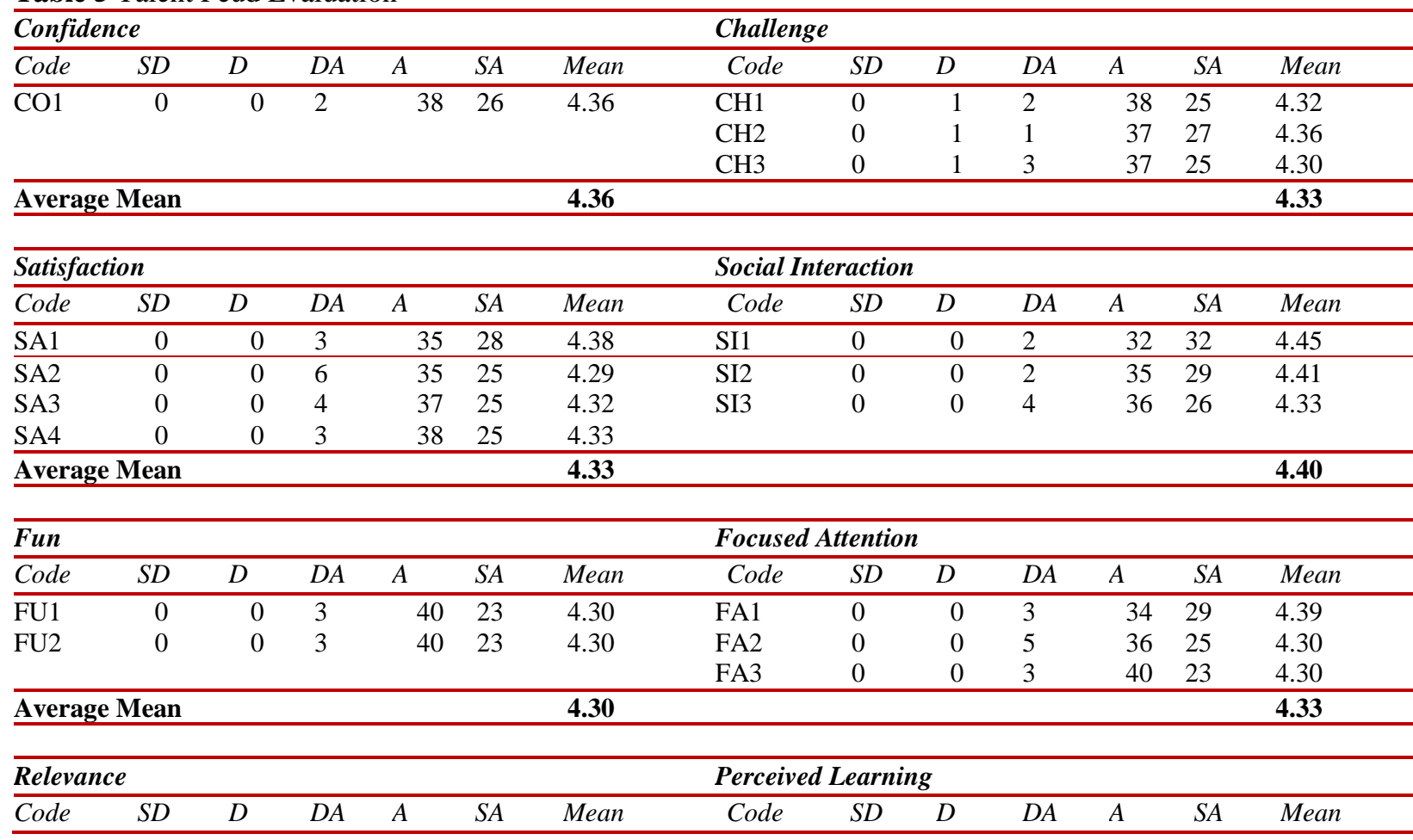


International Journal of Advanced Technology and Engineering Exploration, Vol 8(76)

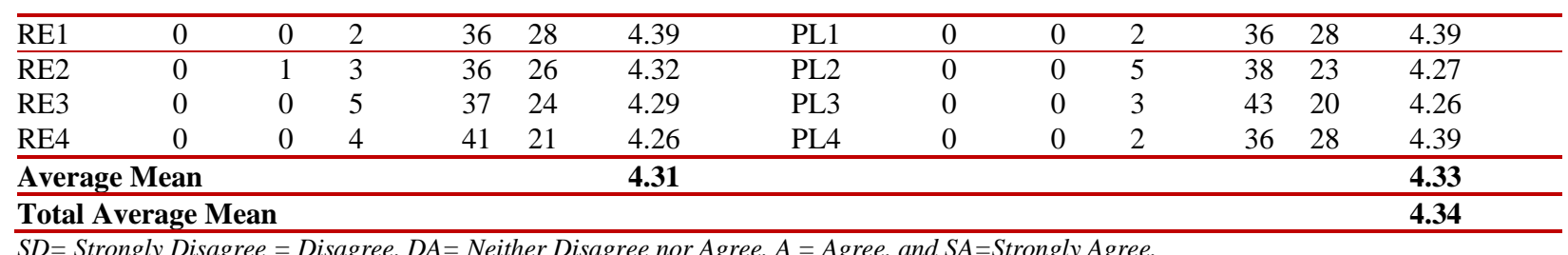

\subsection{Talent mind}

Table 6 presents the participants' perception of

Talent Mind's implementation in the learning session.

From the participants' responses, it is clear that the participants agreed and strongly agreed that Talent Mind, a non-digital game, is fun, with $98.5 \%$ of participants agreeing and strongly agreeing with this statement. All the items measuring Perceived
Learning's element have recorded more than $90.0 \%$ agreeability from the participants. This scenario indicated that the Perceived Learning element contributed to the most pleasant user experience in learning External Selection and Internal Selection topics.

Table 6 Talent mind evaluation

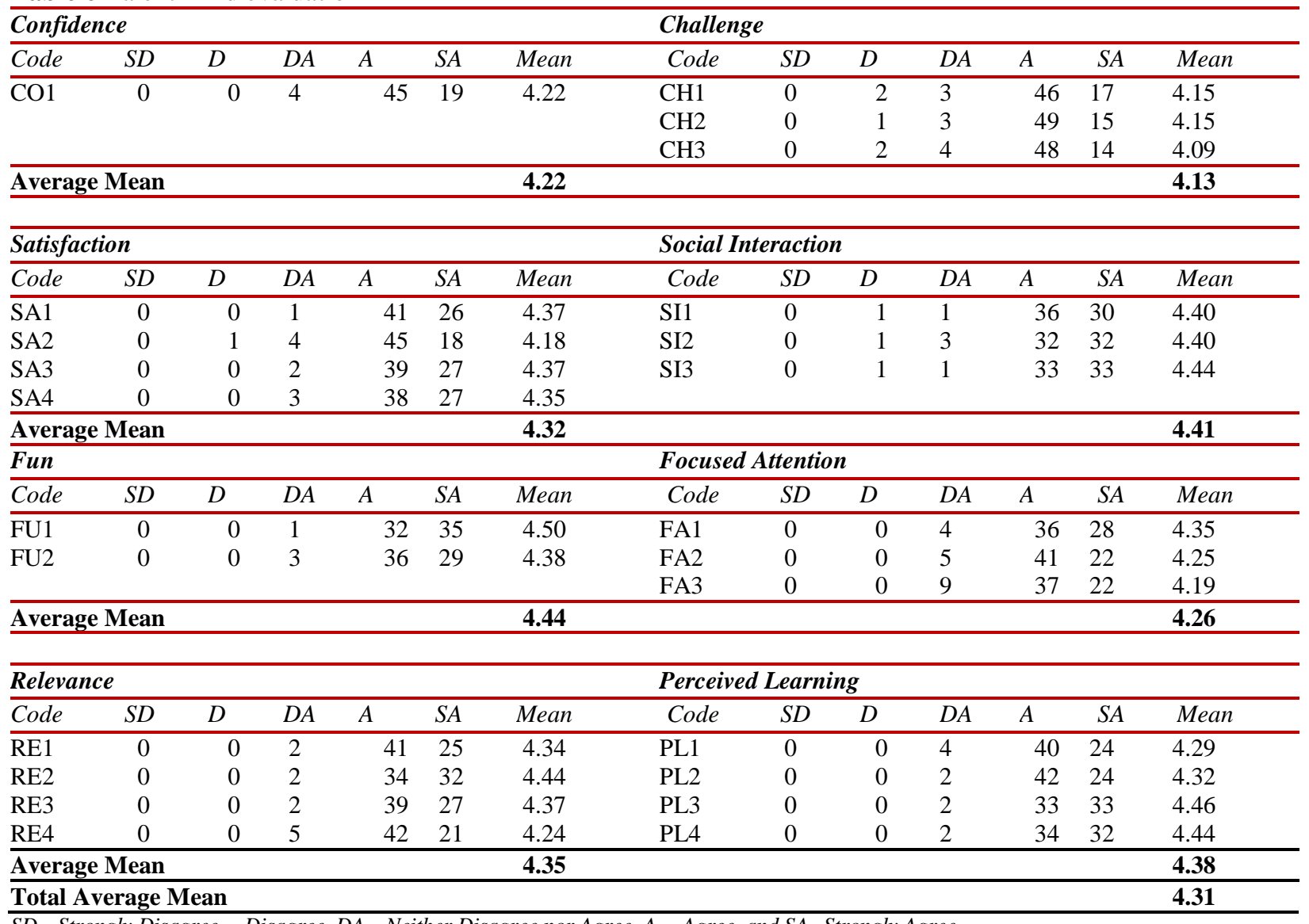

$S D=$ Strongly Disagree $=$ Disagree, $D A=$ Neither Disagree nor Agree, $A=$ Agree, and SA=Strongly Agree.

\subsection{Talent gram}

The result regarding the Talent Gram evaluation is provided in Table 7. The findings indicated that $96.9 \%$ of participants agree and strongly agree that the task gave them a satisfying feeling of accomplishment when they completed the Talent
Gram non-digital game session. About $98.4 \%$ of participants reported they would be recommended the Talent Gram to their members. The Satisfaction element is the highest element with an average mean of $4.37(87.4 \%)$ compared to other elements contributing to Talent Gram's user experience. More 
than $90.0 \%$ of participants believe that the Talent Gram is appropriately challenging and provides new challenges at an appropriate pace. According to the Satisfaction element results, $92.2 \%$ of participants agree and strongly agree that Talent Gram does not become monotonous as it progresses. Based on Table 5. $90.6 \%$ of participants reported that they forgot about their immediate surroundings while playing the Talent Gram non-digital game. Moreover, 93.8\% of participants agree and strongly agree that something interesting at the beginning of the Talent Gram captured their attention.

Table 7 Talent gram evaluation

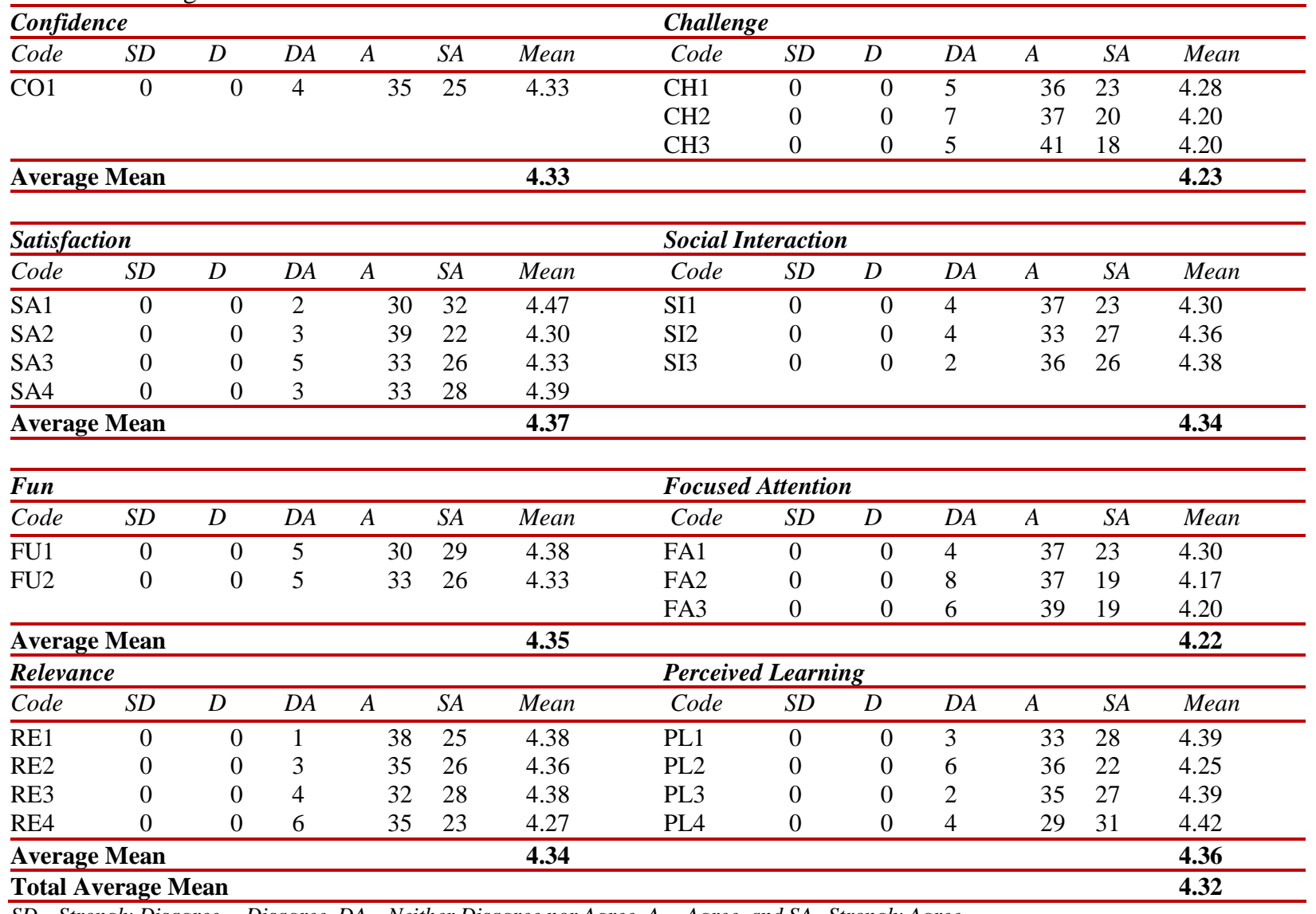

$S D=$ Strongly Disagree $=$ Disagree, $D A=$ Neither Disagree nor Agree, $A=$ Agree, and $S A=$ Strongly Agree.

\section{Discussion}

Regarding the user experiences, all the TCM components, Talent Race, Talent Feud, Talent Mind, and Talent Gram, achieved high percentages of positive responses. The Talent Feud was the highest ranking in terms of preferred components compared to other components. The second preferred component was Talent Race, followed by Talent Gram and finally Talent Mind. TCM offered the participants user experiences in a collaborative learning environment. Besides, every component offered the opportunity to utilize digital and nondigital games in teaching and learning. Students get more involved and engaged in learning by contributing to the games' discussions, and team collaboration provides better problem-solving related to the course content when adopting digital and nondigital-based learning $[1,5]$. This study advances the literature on the learners' learning experiences using traditional and digitalized games. It provides valuable insights that TCM components play a vital role in students' learning experience and process. This study also reveals that students' level of challenge, confidence, satisfaction, social interaction, fun, focused attention, relevance, and perceived learning increased when students adopted collaborative learning, together with the domains involved, i.e., cognitive, affective, and psychomotor. The experience of users in collaborative learning has relatively connected when using traditional and 
digital games, which are fundamental approaches for user learning experiences and performance [14, 20, 22]. To mitigate the challenges of education and blended learning environment, this study meets the demand of pedagogical transformation, which offers ways for a new learning environment beyond traditional classroom approaches.

Overall, this study has revealed that Talent Race, Talent Feud, Talent Mind, and Talent Gram, as collaborative learning complement traditional classroom teaching, therefore enhancing students' experience and engagement [14]. Furthermore, by participating in collaborative learning, the goals of sharing emotions, feelings, values, and ideas can facilitate students' positive learning, behavioural and social outcomes [16-18], [23]. Despite intentions to motivate and engage students' learning experience, collaborative learning approaches can close the gaps of students' intellectual and competencies skills, such as critical thinking, creativity, innovation, negotiations, teamwork, problem-solving, and decision-making $[6,7][10,11]$. With greater attention to collaborative learning, students and educators can enhance the benefits of digital and nondigital games, responsive to learners' needs of education, and support talent domains (e.g., cognitive, affective, and psychomotor).

\section{Conclusion and future work}

This study's findings can be used as a guideline for the higher institutions to incorporate traditional learning with technology for students and educators. Thus, higher institutions' management needs to emphasize challenge, confidence, satisfaction, social interaction, fun, focused attention, relevance, and perceived learning components to gain collaborative learning advantages. Indeed, the key findings' implications indicate, that students' academic key performance and higher institutions generally help improve knowledge attainment, productivity, and competence. As a collaborative learning allows students and educators access to learning opportunities, higher education can considerably achieve national education development goals and pedagogy learning flexibility. Although this study provides useful insights yet, a few limitations should be considered. Firstly, the key findings of a MEEGA+ Model had only evaluated students' experience when playing digital and non-digital games for the TCM components. User experience can only be evaluated students' involvements in the gaming tasks, including their perception of learning, feelings, pleasured, and interactions with the games.
Further studies can include usability factors that evaluate the degree of educational games used by specific students to achieve specific goals with effectiveness and effectivity. For usability, four important components can be evaluated: a) aesthetics, b) learnability, c) operability and d) accessibility. Secondly, the small sample data cannot be generalized to other groups of students in different programs and institutions. The inclusion of a low sample size might produce different findings and did not represent students' overall experience when using the educational games. Therefore, future studies should increase students' participation in different programs and institutions to allow greater generalization of the results. Thirdly, this present study analyses only descriptive analysis of students' experience by looking at the mean and standard deviation values. As this study is based on students' behaviours and experience in collaborative learning, future studies should evaluate the impact of MEEGA+ Model components (user experience and usability) on students' performance, motivation, and engagement using advanced data analysis. Lastly, students' experience and usability towards the performance, motivation, and engagement can be increased when the existence of mediating variables (e.g., support, self-efficacy, cognitive, affective, and psychomotor) and moderating variables (e.g., age, gender, and race) in the relationships are examined.

\section{Acknowledgment}

We want to express our sincere thanks to UiTM and the Ministry of Higher Education, Malaysia, for sponsoring this research by using the Fundamental Research Grant Scheme (FRGS) funding 600-IRMI/FRGS 5/3 (210/2019). Their support is much appreciated. We also would like to express our gratitude to all respondents directly or indirectly involved in this study.

\section{Conflicts of interest}

The authors have no conflicts of interest to declare.

\section{References}

[1] Onofrei G, Ferry P. Reusable learning objects: a blended learning tool in teaching computer-aided design to engineering undergraduates. International Journal of Educational Management. 2020; 34(10):1559-75.

[2] Rasheed RA, Kamsin A, Abdullah NA. Challenges in the online component of blended learning: a systematic review. Computers \& Education. 2020; 144:1-17.

[3] Vanslambrouck S, Zhu C, Lombaerts K, Philipsen B, Tondeur J. Students' motivation and subjective task value of participating in online and blended learning environments. The Internet and Higher Education. 2018; 36:33-40. 
[4] Estacio RR, Raga Jr RC. Analyzing students online learning behavior in blended courses using Moodle. Asian Association of Open Universities Journal. 2017; 12(1):52-68.

[5] Bayrak T, Akcam B. Understanding student perceptions of a web-based blended learning environment. Journal of Applied Research in Higher Education. 2017; 9(4):577-97.

[6] Dwivedi A, Dwivedi P, Bobek S, Zabukovšek SS. Factors affecting students' engagement with online content in blended learning. Kybernetes. 2019; 48(7):1500-15.

[7] Ghazal S, Al-Samarraie H, Wright B. A conceptualization of factors affecting collaborative knowledge building in online environments. Online Information Review. 2019; 44(1):62-89.

[8] Isaias P. Model for the enhancement of learning in higher education through the deployment of emerging technologies. Journal of Information, Communication and Ethics in Society. 2018; 16(4):401-12.

[9] Wieser D, Seeler JM. Online, not distance education: the merits of collaborative learning in online education. In The Disruptive Power of Online Education 2018:125-46. Emerald Publishing Limited.

[10] Sivapalan S. Sustainability, blended learning and the undergraduate communication skills classroom: negotiating engineering undergraduates' expectations and perceptions. On the Horizon. 2017; 25(1):7-23.

[11] Chan SC, Wan CJ, Ko S. Interactivity, active collaborative learning, and learning performance: The moderating role of perceived fun by using personal response systems. The International Journal of Management Education. 2019; 17(1):94-102.

[12] Dukuzumuremyi S, Siklander P. Interactions between pupils and their teacher in collaborative and technology-enhanced learning settings in the inclusive classroom. Teaching and Teacher Education. 2018; 76:165-74.

[13] Deckert R, Heymann F, Metz M. Game-based learning as education method in the digital age: experiences at the highest military education institution in germany with online and offline game formats related to developing competencies $\bar{i}$ is the military education institution of the study is führungsakademie der bundeswehr, hamburg. In the Disruptive Power of Online Education 2018:185-204. Emerald Publishing Limited.

[14] Mercer TG, Kythreotis AP, Robinson ZP, Stolte T, George SM, Haywood SK. The use of educational game design and play in higher education to influence sustainable behaviour. International Journal of Sustainability in Higher Education. 2017; 18(3):35984.

[15] Emblen-Perry K. Enhancing student engagement in business sustainability through games. International Journal of Sustainability in Higher Education. 2018; 19(5):858-76.

[16] Barbara J. Measuring user experience in multiplayer board games. Games and Culture. 2017; 12(7-8):62349.
[17] Begy J. Board games and the construction of cultural memory. Games and Culture. 2017; 12(7-8):718-38.

[18] Fjællingsdal KS, Klöckner CA. Green across the board: Board games as tools for dialogue and simplified environmental communication. Simulation \& Gaming. 2020; 51(5):632-52.

[19] Chen J, Wang M, Kirschner PA, Tsai CC. The role of collaboration, computer use, learning environments, and supporting strategies in CSCL: a meta-analysis. Review of Educational Research. 2018; 88(6):799843.

[20] Dimitriadou A, Djafarova N, Turetken O, Verkuyl M, Ferworn A. Challenges in serious game design and development: educators' experiences. Simulation \& Gaming. 2020; 52(10).

[21] Imlig-Iten N, Petko D. Comparing serious games and educational simulations: effects on enjoyment, deep thinking, interest and cognitive learning gains. Simulation \& Gaming. 2018; 49(4):401-22.

[22] Von Gillern S, Alaswad Z. Games and game-based learning in instructional design. International Journal of Technologies in Learning. 2016; 23(4):1-7.

[23] Deif A. Insights on lean gamification for higher education. International Journal of Lean Six Sigma. 2017; 8(3):359-76.

[24] Petri G, von Wangenheim CG, Borgatto AF. MEEGA+: an evolution of a model for the evaluation of educational games. INCoD/GQS. 2016; 3:1-40.

[25] Kapp KM. The gamification of learning and instruction: game-based methods and strategies for training and education. John Wiley \& Sons; 2012.

[26] Zain NH, Zaini H, Zulhemay MN, Baharum A, Bustamam WF, Razak FH. Engaging game design in learning historical patriotic heroes: students' perceptions. Pertanika Journal of Science \& Technology. 2017; 25(S):197-204.

[27] Hawari N, Zain NH, Baharum A. The need of gamified assessment for engaging learning experience. Bulletin of Electrical Engineering and Informatics. 2020; 9(2):722-8.

[28] Naik N. A comparative evaluation of game-based learning: digital or non-digital games? In European conference on games based learning 2014 (p. 437). Academic Conferences International Limited.

[29] Palomino P, Toda A, Oliveira W, Rodrigues L, Cristea A, Isotani S. Exploring content game elements to support gamification design in educational systems: narrative and storytelling. In Brazilian Symposium on Computers in Education (Simpósio Brasileiro de Informática na Educação-SBIE) 2019 (p. 773).

[30] Toda AM, Palomino PT, Oliveira W, Rodrigues L, Klock AC, Gasparini I, et al. How to gamify learning systems? an experience report using the design sprint method and a taxonomy for gamification elements in education. Journal of Educational Technology \& Society. 2019; 22(3):47-60.

[31] Smith BL, MacGregor J, Matthews R, Gabelnick F. Learning communities: reforming undergraduate education. 2009. 
[32] Kuh GD. Excerpt from high-impact educational practices: what they are, who has access to them, and why they matter. Association of American Colleges and Universities. 2008; 14(3):28-9.

[33] Tinto V. Leaving college:rethinking the causes and cures of student attrition. University of Chicago Press, 5801 S. Ellis Avenue, Chicago, IL 60637; 1987.

[34] Schreiner LA, Louis MC, Nelson DD. Thriving in transitions: a research-based approach to college student success. Stylus Publishing, LLC; 2020.

[35] Yue CL, Bjork EL, Bjork RA. Reducing verbal redundancy in multimedia learning: an undesired desirable difficulty? Journal of Educational Psychology. 2013; 105(2):266-77.

[36] Lui S. Use of gasification in vocabulary learning: a case study in Macau. In 4th CELC Symposium Proceedings 2014 (pp. 90-7).

[37] Foulsham T, Farley J, Kingstone A. Mind wandering in sentence reading: decoupling the link between mind and eye. Canadian Journal of Experimental Psychology/Revue canadienne De Psychologie Expérimentale. 2013; 67(1):51-9.

[38] Saravanakumar D, Mohan B, Muthuramalingam T. A study on influence of system parameters on servo pneumatic system and multi-response optimization using taguchi-grey methodology. In applied mechanics and materials 2015 (pp. 901-5). Trans Tech Publications Ltd.

[39] Martin AJ, Dowson M. Interpersonal relationships, motivation, engagement, and achievement: Yields for theory, current issues, and educational practice. Review of educational research. 2009; 79(1):327-65.

[40] Frymier AB, Shulman GM. "What's in it for me?": Increasing content relevance to enhance students' motivation. Communication Education. 1995; 44(1):40-50.

[41] Bacon DR. Reporting actual and perceived student learning in education research. Journal of Marketing Education. 2016; 38(1).

[42] Alqurashi E. Predicting student satisfaction and perceived learning within online learning environments. Distance Education. 2019; 40(1):13348.

[43] Moreno R, Mayer RE. Verbal redundancy in multimedia learning: when reading helps listening. Journal of educational psychology. 2002; 94(1):15663.

[44] Barbera E, Clara M, Linder-Vanberschot JA. Factors influencing student satisfaction and perceived learning in online courses. E-learning and Digital Media. 2013; 10(3):226-35.

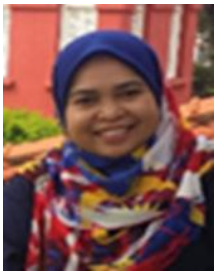

Nurul Hidayah Mat Zain received the Doctor of Philosophy (Visual Informatics) from Universiti Kebangsaan Malaysia (UKM) in 2016. She completed the Bachelor of Computer Science (Software Engineering) and MSc Computer Science (Multimedia System) both from Universiti Putra Malaysia (UPM), Serdang, Malaysia, in 2002 and 2003, respectively. She is currently a Senior Lecturer with the Department of Computer Science (Multimedia Computing), UiTM Cawangan Melaka, Campus Jasin. She published many Scopus and ISI Thomson indexing publications, including journals, proceedings, chapters in books, and articles. She also won several gold medals, diamond awards, and platinum awards in the research and innovation exhibition. She is also a reviewer paper for national and international journals, including Q1 journals, and is actively involved in several grants as project leader and co-researcher. Her research interest is Game Design, Gamification, Serious Game, Game Technology, User Experience, Human-Computer Interaction, and Eye-Tracking.

Email: nuru1417@uitm.edu.my

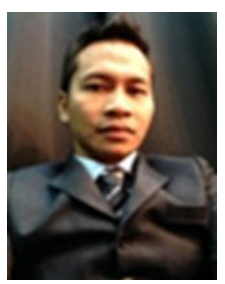

Idris Osman is a senior lecturer at the Faculty of Management and Business, Universiti Teknologi MARA, Melaka Branch, Malacca City Campus. He graduated with Bachelor of Science (Honours), Human Resource Development at Universiti Teknologi Malaysia in 1999-2003, and continued his Master of Science in the same course in 2003-2005. In 2014, he continued his PhD at UiTM Shah Alam in Human Resource Management, and graduated in 2017. He has experience in the industry as an HR practitioner at manufacturing companies in managing human resource management activities such as training and development, industrial relations, recruitment and selection of employees, and matters related to employee welfare. He started his career as a lecturer at UiTM in 2008 until present. His research interests are in management and development of Talent, Training, Communication, Human Resource Management and International Business. He is also active in writing and research, innovation and university consultancy.

Email: idris424@uitm.edu.my 


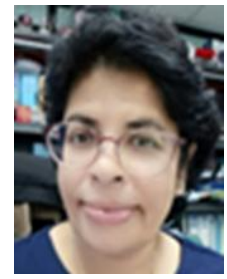

Rachel Samuel received her Doctor of Philosophy (Management) from Universiti Sains Malaysia (USM) in 2009. She completed her Bachelors in Social Sciences and Masters in Social Sciences in USM. She is currently a Senior Lecturer with the Faculty of Business Management (Human Resource Management), UiTM Cawangan Melaka, Campus Bandaraya Melaka. She has published papers on human resource issues, including employability, work-life balance issues in addition to issues of women at the workplace. She has also published books on social issues mainly rape and domestic violence. She is also a reviewer for conferences and national journals, and is actively involved in several grants as project leader and coresearcher. Her research interest is Human Resource issues at the workplace, gender related issues, emotional intelligence, and mental health.

Email: rachelsam@uitm.edu.my

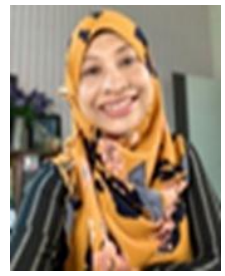

Suhailah Kassim received the Master in Business Administration from Universiti Utara Malaysia (UUM) on 2010. She completed the Bachelor of Business Administration (Human Resource Management) from Open Universiti Malaysia (OUM), in 2007. She is currently a Senior Lecturer with the Faculty of Business Management (Human Resource) UiTM Cawangan Melaka, Campus Bandaraya Melaka. She has won several gold medals, diamond awards, and platinum awards in the innovation exhibition. Her research interest is Interactive Learning, Engagement, Change Management, Motivation Learning and Talent Management.

Email: suhailahk@uitm.edu.my

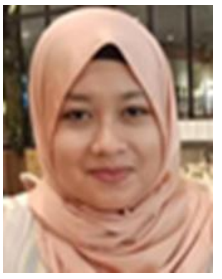

Suraya Hamimi Mastor received the Master in Business Administration from Universiti Utara Malaysia (UUM) on 2012. She completed the Bachelor of Business Administration (Human Resource Management) from Open Universiti Malaysia (OUM), in 2009. She is currently a Senior Lecturer with the Faculty of Business Management (Human Resource) UiTM Cawangan Melaka, Campus Bandaraya Melaka. She has won several gold medals, diamond awards, and platinum awards in the innovation exhibition. Her research interest is Interactive Learning, Engagement, Change Management, Motivation Learning and Talent Management.

Email: surayahamimi@uitm.edu.my

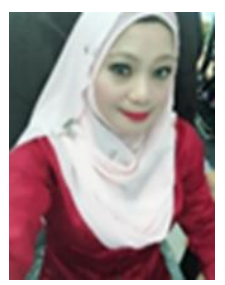

Halimahton Borhan is an Associate Professor in the Department of Economics, Faculty of Business Management, Universiti Teknologi MARA, Melaka campus. She has a bachelor's degree in Economics from International Islamic University, Malaysia (1997). In 2005 she obtained a Master of Business Administration (Multimedia Finance) from Multimedia University Malaysia and in 2012 she is conferred the degree of Doctor of Philosophy in Business Management (Economics) by Multimedia University Malaysia. Her research interests and publications are mainly in the areas of Environmental, Green and Sustainable Development, Economics. She published many Scopus and WOS indexing publications, including journals, proceedings, chapters in books, and articles. She also won several gold medals in the research and innovation exhibition. She is also a reviewer paper for national and international journals, including Scopus journals, and involved in a grant as project leader.

Email: hali@uitm.edu.my 